\title{
The influence of gold nanoparticles on the thermal conductivity of water solutions of graphen
}

\author{
V.V. Korskanov ${ }^{1}$ (0000-0001-8204-5728), O.M. Fesenko' ${ }^{1}$ T.V. Tsebrienko ${ }^{1}$, O.P. Budnik ${ }^{1}$, \\ V.B. Dolgoshey ${ }^{2}(0000-0002-0147-3534)$ \\ 1 - Institute of physics of NAS of Ukraine, av. Nauki 46, Kyiv, 03028, Ukraine \\ Tel.: +380445251220 \\ E-mail: korskanov_valera@i.ua,fesenko@iop.kiev.ua \\ 2 - National Technical University of Ukraine "Igor Sikorsky Kyiv Polytechnic Institute”, av. Peremogy, Bldg. 19, Kyiv, \\ 03056, Ukraine \\ Tel.: +380931234802 \\ E-mail:vdolgoshey@ukr.net
}

Article info: received 18.11.2019, revised 22.11.2019, accepted 06.12.2019

Korskanov, V.V., Fesenko, O.M., Tsebrienko, T.V., Budnik, O.P., Dolgoshey, V.B. (2019) The influence of gold nanoparticles on the thermal conductivity of water solutions of graphen 4(45), doi: 10.26909/csl.4.2019.2

The objects of study were water dispersions of raw graphene (hereinafter referred to as graphene-n), higher degree of purification of graphene samples (hereinafter graphene), and nanoparticles of graphene-Au nanoparticles based on them.

The thermal conductivity of water graphene dispersions and water dispersions of gold graphene nanoparticles nanostructures at different temperatures and component ratios was investigated. The values of effective thermal conductivity of dry nanofillers are calculated. The temperature dependences of the thermal conductivity of the nanofillers were obtained. It is found that the in-thermal conductivity of water dispersions of purified graphene is higher than the thermal conductivity of raw graphene as a result of better packing of nanoparticles in pure graphene nanofillers compared to raw. The effect of enhancement of thermal conductivity of gold nanoparticles, which is accompanied by higher absolute values of thermal conductivity of nanoparticles of graphene-nanoparticles of gold than the corresponding graphene, was revealed. At the same time, there is a significant difference in thermal conductivity between nanoparticles of graphene nanoparticles of gold.

It is established that higher values of thermal conductivity of graphene-nanoparticles nanostructures of gold are the result of the reinforcing action of a gold nanoparticle substrate, which is formed as a result of joint sedimentation with graphene during the formation of nano-flakes from water solution during evaporation of water.

Key words: hereinafter graphene, nanoparticles, thermal conductivity.

\section{Вплив наночастинок золота на теплопровідність водних розчинів графену}

\author{
В.В. Корсканов ${ }^{1}$, О.М. Фесенко ${ }^{1}$, Т.В. Цебрієнко ${ }^{1}$, О.П. Будник ${ }^{1}$, В.Б. Долгошей ${ }^{2}$ \\ 1 - Інститут фізики НАН України, Київ, Україна \\ 2 - Національний технічний університет України "Київський політехнічний інститут імені Ігоря Сікорсько- \\ го”, Київ, Україна
}

Досліджено теплопровідність водних дисперсій графену і водних дисперсій наноструктур графен-наночастинки золота при різних температурах та співвідношеннях компонентів. Розраховані значення ефективної теплопровідності сухих нанофлейків. Отримані температурні залежності теплопровідності нанофлейків. Встановлено, що вищі значення теплопровідності наноструктур графен-наночастинки золота є результатом підсилюючої дії підложки із наночастинок золота, яка утворюється в результаті сумісної седиментації з графеном при формуванні нанофлейків із водного розчину при випаровуванні води. 


\section{Вступ}

Теплопровідність індивідуальної наночастинки графену (ГФН), розрахована за допомогою чисельного моделювання, при кімнатній температурі становить 3000 - $3500 \mathrm{Bт} /(\mathrm{M} \cdot \mathrm{K})$ [1]. У той же час загальна теплопровідність графенових наноструктур об'єднаних у нанофлейки (НФ) в результаті високого термічного міжконтактного опору між сусідніми наночастинками ГФН значно нижча (порядку 10 $100 \mathrm{Bт} /($ м.К)) [2]. Крім того, в результаті самоорієнтаціi анізометричних частинок графену при формуванні графенових нанофлейків виникають наноструктури (НC) зі значною анізотропією теплопровідності вздовж осі самоорієнтаціїі (паралельно площині підкладки - in plane) та перпендикулярно їй (through plane) [3]. У випадку водних дисперсій при зменшенні вмісту води нанопластинки ГФН під дією гравітаційних сил проявляють тенденцію до самовпорядкування паралельно площині підкладки створюючи, таким чином, морфологію типу «риб'ячої луски». In plane-теплопровідність таких наноструктур значно перевищує through plane-теплопровідність. Водні дисперсіїі таких наноструктур високоефективні в якості охолоджуючих, або теплотранспортних рідин завдяки високій теплопровідності та низької в'язкості у напрямку течії.

Для підвищення теплопровідності створюють нанокомпозити графен-нанометал, в яких наночастинки металу мають зменшити міжконтактний термічний опір [4, 5]. 3 іншого боку, специфічні властивості контактів графен-нанометал роблять їх корисними у багатьох галузях нанонауки, зокрема у наноелектроніці, у Раман-спектроскопії [4, 6, 7]. Нанокомпозити на основі графену та наночастинок металів широко використовуються в якості біосенсорів. У сучасних нанотехнологіях використовують біосенсори: графен-Pt, графен-Pd, графен-Au, графен-Ag, графен-Ni, графен-Cu. Також відомі біосенсори на основі графену та оксидів металів (NiO, $\mathrm{CuO}, \mathrm{ZnO}, \mathrm{TiO}_{2}$ ), сплавів, біметалів, а також біосенсори графен-триметал [4].

У цій роботі представлено результати дослідження концентраційних залежностей теплопровідності водних дисперсій графену i наноструктур графен-наночастинки золота, розрахована ефективна in plane-теплопровідність сухих нанофлейків та отримані температурні залежності теплопровідності нанофлейків графену та нанокомпозитів графен-наночастинки $\mathrm{Au}$.

\section{Матеріали та методи дослідження}

Об’єктами досліджень слугували водні дисперciї неочищеного графену (далі - графен-н), зразки графену вищого ступеню очистки (далі - графен) та наноструктури графен-наночастинки Аu на їх основі. На рис. 1 приведені мікрофотографії графену та наноструктур графен-наночастинки Au.
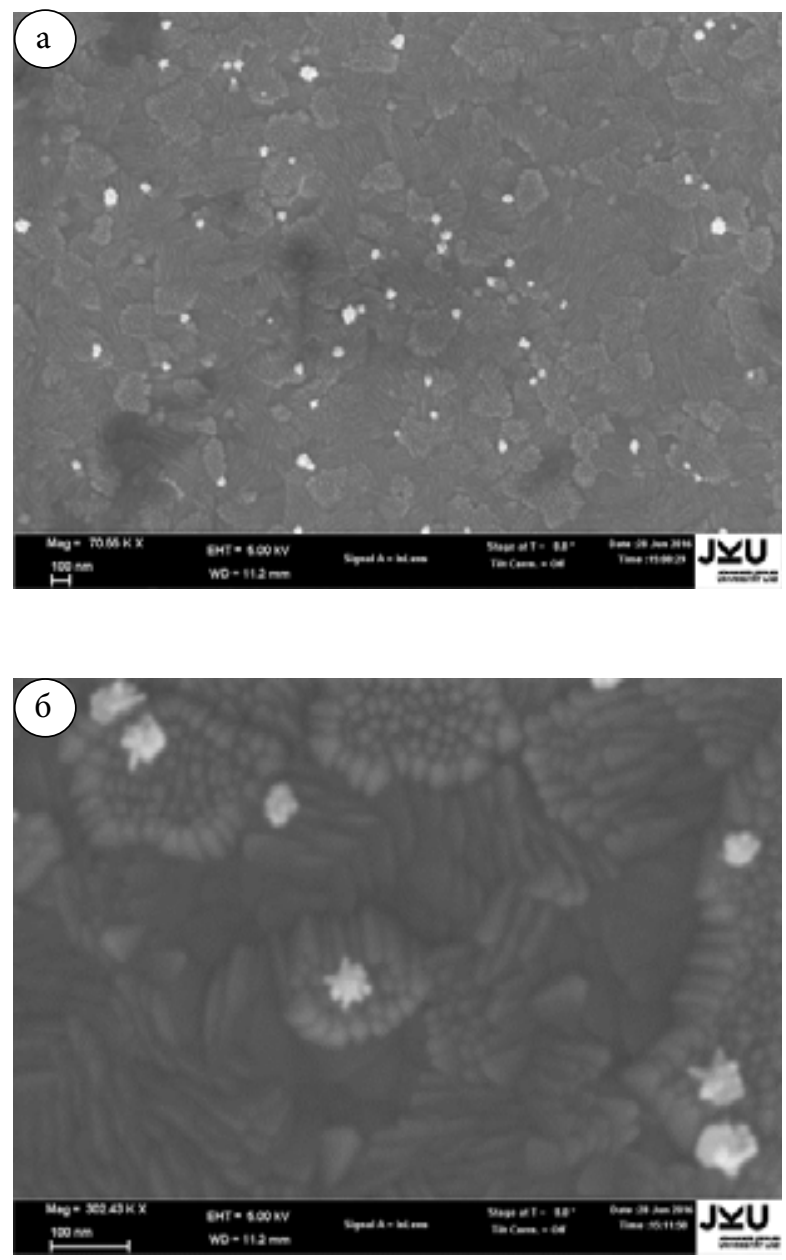

Рис. 1. Мікрофотографії SEM нанокомпозиту графен-наночастинки золота у різних масштабах

3 мікрофотографій можна зробити висновок, що графен має характеристичні розміри порядку 150 - 200 нм у площині. Наночастинки Аu мають середній розмір близько 50 нм та зіркоподібну форму. У сухих нанокомпозитах графен орієнтований паралельно площині підкладки, а наностари рівномірно розподілені на поверхні зразка.

Водні дисперсії (WD) графену отримували шляхом додавання 1 мг графенового порошку до 500 мл дистильованої води та подальшого ультразвукового диспергування протягом 5 хвилин. Отриманий таким чином розчин (співвідношення компонентів вода/нанонаповнювач $w=0,002$ мас. частини) поміщали у вимірювальну калориметричну циліндричну комірку діаметром 8 мм і висотою 30 мм. Для 
приготування метал-графенових наноструктур до 0,2 мас. \% водного розчину графену додавали 20 мкл розчину наночастинок Аu і завантажували у вимірювальну комірку. Зразок зважували та поміщали у вимірювальний модуль і охолоджували до $-10^{\circ} \mathrm{C}$. Потім вимірювали тепловий потік через зразок при нагріванні до температури $60{ }^{\circ} \mathrm{C}$ в режимі постійного теплового потоку. Після першого сканування проводили контрольне зважування зразка, випаровуванням видаляли частину вологи безпосередньо у вимірювальній комірці та повторювали процес сканування. Досліджування проводили до повного видалення вологи. Для адекватності подальшого порівняння результатів всі зразки досліджувались при ідентичних умовах - однаковому температурному інтервалі і тепловому потоці через зразки.

Дослідження теплопровідності у температурному інтервалі від $30{ }^{\circ} \mathrm{C}$ до $60{ }^{\circ} \mathrm{C}$ проводили за допомогою калориметричного модуля, принцип роботи якого детально було описано в [8].

Особливості налаштування і конструкція модуля вигідно відрізняється від іншого типового обладнання подібного типу тим, що в ньому реалізований принцип стаціонарного теплового потоку, а не постійної швидкості нагрівання, як у переважної більшості подібного обладнання. При дослідженнях у цьому режимі компенсуються підвищені теплові втрати при високих температурах та є змога розрахувати in plane-теплопровідність за умов розповсюдження стаціонарного теплового потоку через бічні поверхні циліндричного зразка заданого розміру [9].

Блок-схема приладу приведена на рис. 2. Зразок 1 поміщають у циліндричну вимірювальну комірку. Паралельно бічним поверхням комірки розміщені вимірювальні термобатареї 3, які фіксують тепло-

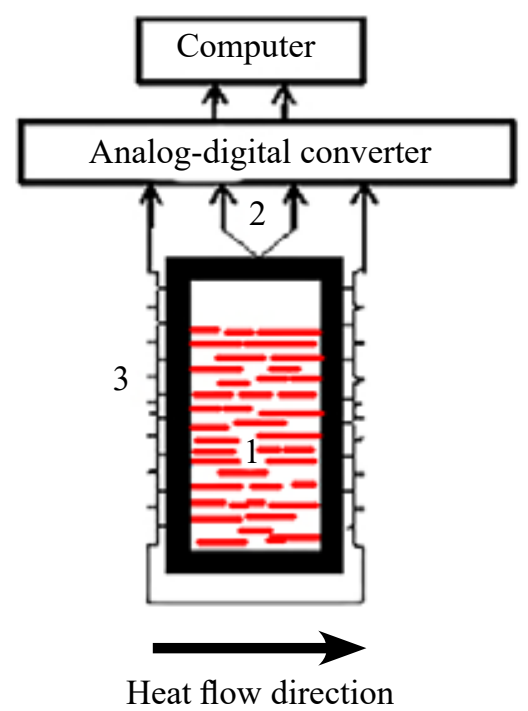

Рис. 2. Блок-схема калориметричного блоку вий потік через бічні поверхні зразка. Одночасно фіксується поточна температура за допомогою термопари 2. Сигнали $з$ вимірювальних термобатарей та термопари поступають на високочутливий багатоканальний аналогово-цифровий перетворювач i, далі, через USB-порт подається в комп'ютер, в якому оброблюються попередньо встановленим відповідним програмним забезпеченням.

Типова скануюча термограма наноструктур показана на рис. 3. Поточний вміст води в нанокомпозитах визначався по величині піку плавлення на термограмах, а значення теплопровідності в інтервалі температур стаціонарного теплового потоку розраховували по величині теплового потоку та по коефіцієнтах, попередньо отриманих від калібрації по дистильованій воді.

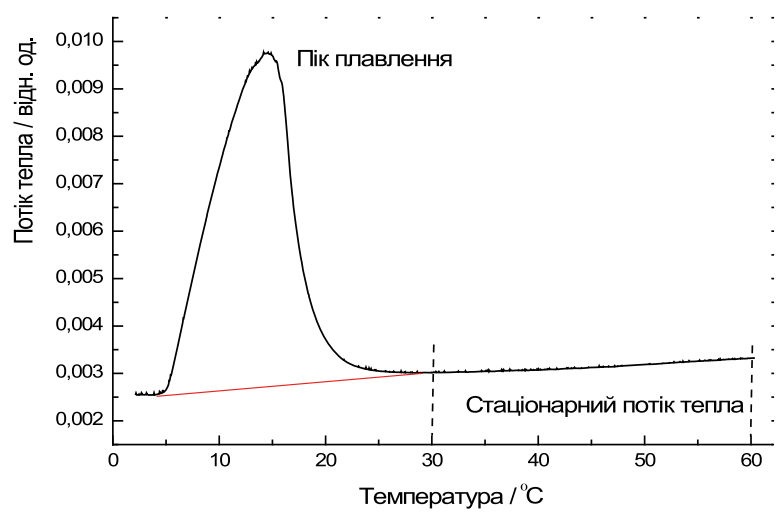

Рис. 3. Типова ДСК термограма нанокомпозитів

\section{Результати та їх обговорення}

3 приведених на рис. 4 експериментальних термограм досліджених зразків видно, що симбатно зменшенню маси зразків (позначені цифрами на графіках у міліграмах) знижуються значення стаціонарного теплового потоку при температурах вищих $30^{\circ} \mathrm{C}$. Це означає зменшення термічного опору, або збільшення теплопровідності.

Калібровку комірки по теплопровідності проводили також по термограмам плавлення дистильованої води у температурній області стаціонарного теплового потоку (вище температури плавлення - при $t \geq 30^{\circ} \mathrm{C}$ ).

Коефіцієнти розрахунку для кожної температури $k_{\lambda}$ визначали як

$$
k_{\lambda}=\lambda_{\text {water tabl. }} / \Delta \mathrm{u}_{\text {water }},
$$

де $\lambda_{\text {water tabl. }}-$ табличні значення теплопровідності води [10], $\Delta \mathrm{u}_{\text {water }}$ - значення стаціонарного теплового потоку на термограмі плавлення води. 

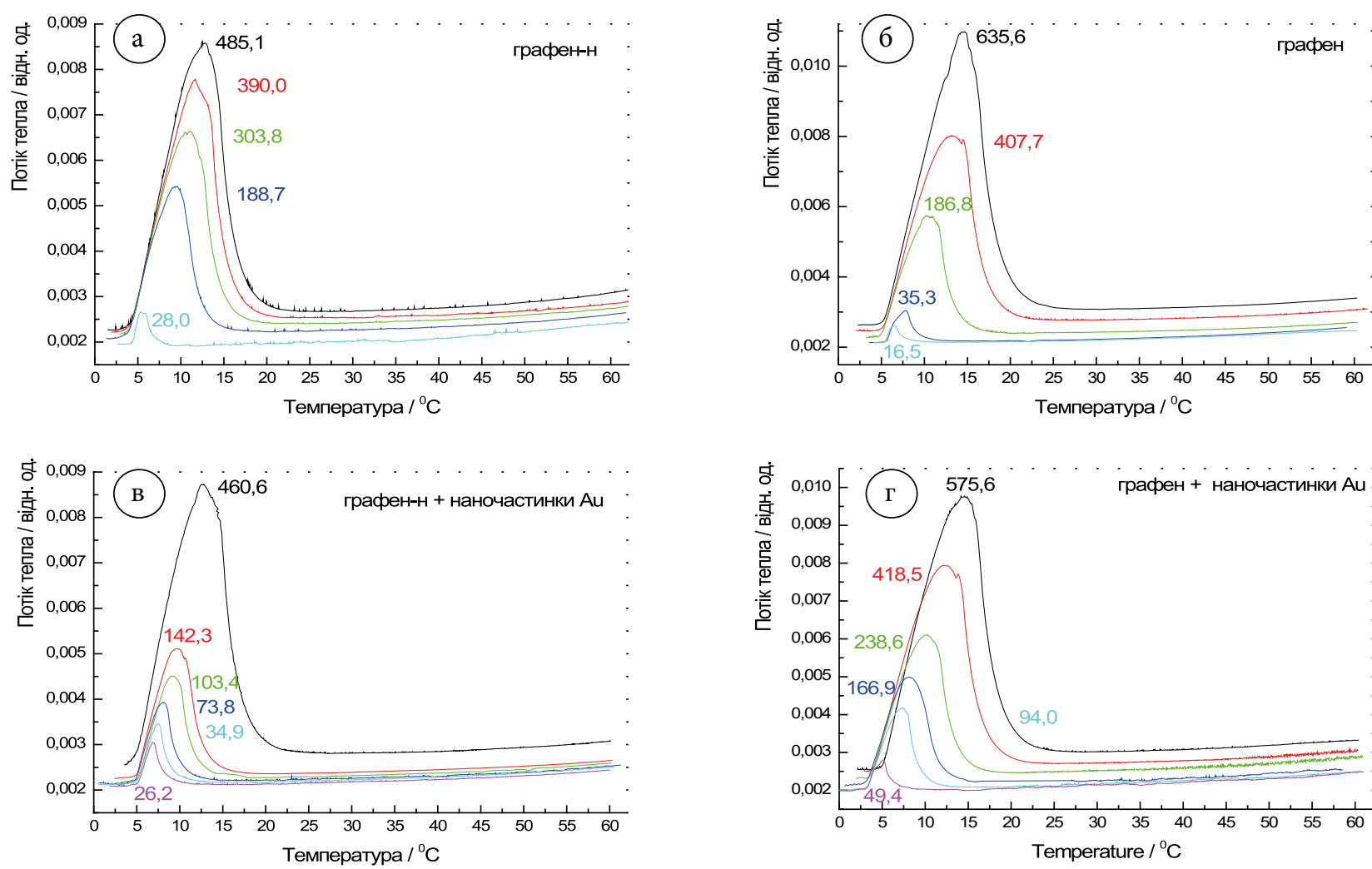

Рис. 4. Скануючі термограми нанокомпозитів.

а) - графен-н, б) - графен, в) - графен-н + наночастинки Аu, г) - графен + наночастинки Аu.

Числами позначено вагу зразків у міліграмах

Тоді теплопровідність WD можна розрахувати як

$$
\lambda=\Delta \mathrm{u}_{W D} \cdot k_{\lambda} / m_{W D}
$$

де $\Delta \mathrm{u}_{W D}$ - величина стаціонарного теплового потоку на термограмах для WD (тобто, при температуpax вище $30^{\circ} \mathrm{C}$ (рис. 3), $m_{W D}$ - маса відповідного зразка.

3 приведених на рис. 5 температурних залежностей теплопровідності графену та графен-наночастинки золота НС видно, що при низькому вмісті нанонаповнювача відбувається ледь помітне підвищення теплопровідності (рис.4а та рис. 4б). Це значить, що у цьому інтервалі складів процеси теплопереносу контролюються неперервною водною фазою. При наближенні до $w=0,5$ відбувається значне підвищення теплопровідності за рахунок передачі тепла від наночастинки до наночастинки (оскільки при такому складі відстань між ними зменшується, наближаючись до довжини вільного пробігу фононів). Позитивний температурний коефіцієнт теплопровідності може бути результатом зменшення відстані між сусідніми наночастинками за рахунок теплового розширення. Слід також відмітити, що помітне зростання теплопровідності наноструктур графен-наночастинки золота відбувається вже при $w \approx 0,2$ (рис. 4в та рис. 4г).

Для зручності подальшого аналізу та обговорення результатів ми побудували порівняльні концентраційні залежності теплопровідності для всіх зразків в однаковому масштабі для двох крайніх температур $-30^{\circ} \mathrm{C}$ та $60^{\circ} \mathrm{C}$ (рис. 6).

Аналізуючи результати, наведені на рис. 6, можна зробити наступні висновки:

1. Теплопровідність водних дисперсій очищеного графену вища ніж теплопровідність неочищеного, як результат кращої упаковки наночастинок у нанофлейках чистого графену у порівнянні з неочищеним (рис. 6а).

2. Вищі абсолютні значення теплопровідності наноструктур графен-наночастинки золота ніж відповідних графенів можна розглядати як ефект підсилення провідності тепла наночастинками золота (рис. 6б, рис. 6в).

3. Значної відмінності теплопровідності між метал-графеновими наноструктурами обох видів не виявлено (рис. 6г). Це означає, що ефект підсилення теплопровідності наночастинками золота дієвий як для очищеного графену, так і для неочищеного. 

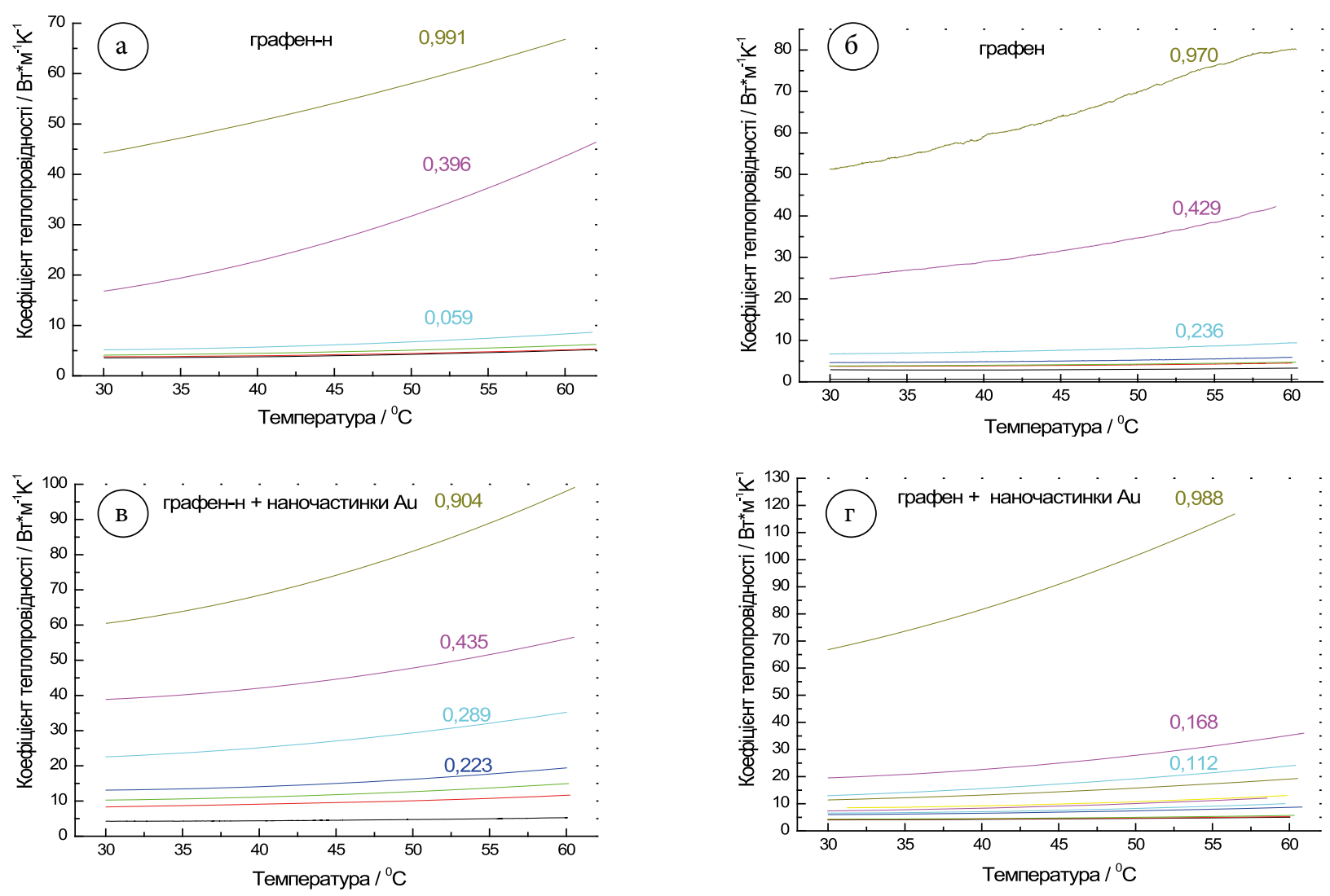

Рис. 5. Температурна залежність теплопровідності.

a) - графен-н, б) - графен, в) - графен-н + наночастинки Au, г) - графен + наночастинки Au.

Числами позначено вагу зразків у міліграмах

Таким чином, можна зробити загальний висновок про те, що формування нанофлейків графен-наночастинки золота із водних дисперсій відбуваються по механізму одночасної седиментації компонентів у водному розчині. При цьому важчі наночастинки золота (молекулярна маса $\mathrm{Au}=197$ ) створюють своєрідну підкладку для легшого графену (молекулярна маса вуглецю 12), що сприяє переносу тепла через нанофлейки метал-графен-наночастинки золота.

Оцінити теплопровідність «сухих» наноструктур та температурний коефіцієнт зростання теплопровідності $d \lambda / d t$ можна шляхом екстраполяції експериментальних даних до $w=1,0$ (рис. 7, табл. 1).

Згідно уявлень теорії теплопровідності, зростання абсолютних значень теплопровідності у ряду графен-н $\rightarrow$ графен $\rightarrow$ графен-н + наночастинки золота $\rightarrow$ графен + наночастинки золота означає під- вищення густини упаковки наноструктур, а підвищення температурного коефіцієнта теплопровідності - зменшенню дефектності цих наноструктур за рахунок теплового розширення їх анізометричних складових [11].

\section{Висновки}

Вивчено теплопровідність водних дисперсій графену і водних дисперсій наноструктур графен-наночастинки золота при різних температурах та співвідношеннях компонентів.

Отримано значення ефективної теплопровідності сухих нанофлейків та розраховано температурні залежності теплопровідності нанофлейків.

Встановлено, що in plane-теплопровідність водних дисперсій очищеного графену вища ніж те-

Таблиця 1.

Термічний коефіцієнт теплопровідності

\begin{tabular}{|c|c|c|c|c|}
\hline Зразок & Графен-н & Графен & Графен-н + наночастинки золота & Графен + наночастинки золота \\
\hline$d \lambda / d t, \mathrm{Bт} /\left(\mathrm{M} \cdot \mathrm{K}^{2}\right)$ & 0,75 & 1,07 & 1,52 & 1,83 \\
\hline
\end{tabular}



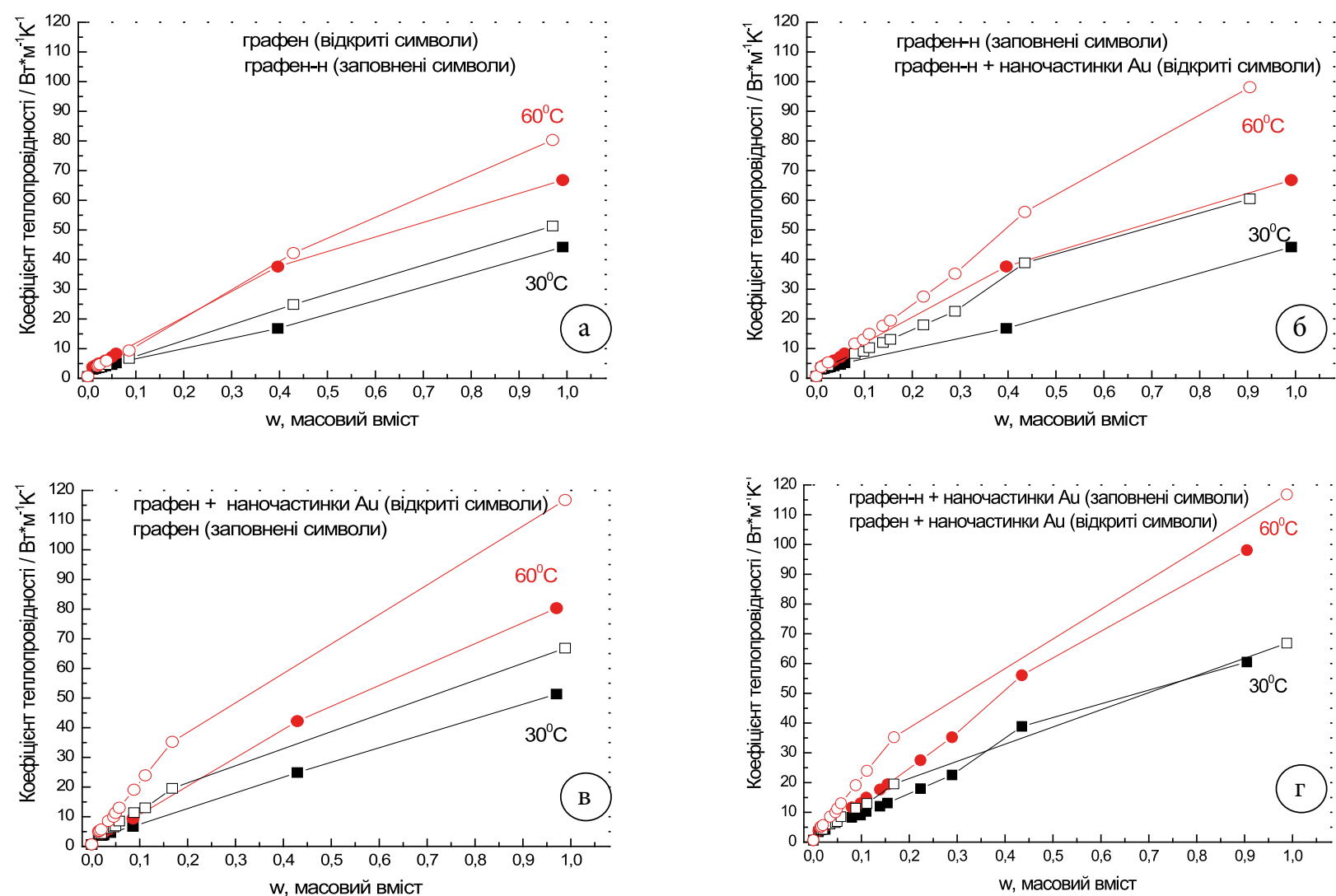

Рис. 6. Концентраційні залежності теплопровідності нанокомпозитів

плопровідність неочищеного, як результат кращої упаковки наночастинок у нанофлейках чистого графену у порівнянні з неочищеним.

Виявлено ефект підсилення провідності тепла наночастинками золота, який супроводжується вищими абсолютними значеннями теплопровідності наноструктур графен-наночастинки золота ніж відповідних графенів. У той же час значної відмінності

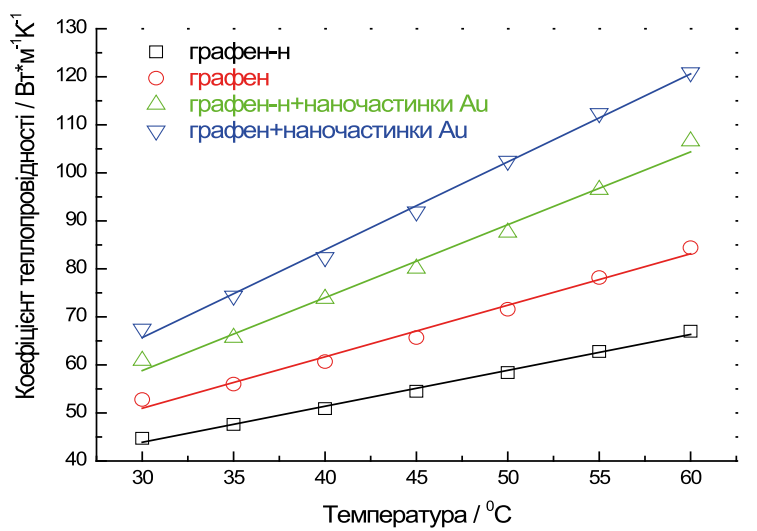

Рис. 7. Температурна залежність сухих нанокомпозитів теплопровідності між наноструктурами графен-наночастинки золота не виявлено.

Встановлено, що формування нанофлейків графен-наночастинки золота із водних дисперсій відбуваються по механізму одночасної седиментації компонентів у водному розчині. При цьому важчі наночастинки золота створюють своєрідну підкладку для легшого графену, яка сприяє переносу тепла через нанофлейки графен-частинки золота.

\section{References}

1. Ghosh, S., Calizo, I., Teweldebrhan, D. et. al. Extremely high thermal conductivity in graphene: Prospects for thermal management application in nanoelectronic circuits // Appl. Phys. Lett. - 2008. - Vol.92. - P. 1519 - 1527.

2. Shahil, K.M., Balandin, A. Thermal properties of graphene and multilayer graphene: Application in thermal interfase materials // Solid State Communications. - 2012. - Vol.152. - P. 1331 - 1340.

3. Song, Yu., Yang, Ch., Liu, D., Lin, Y., Nan, C.W. Self-orientation of graphite-nanoplates induces anisotropy ofnanoplates-epoxy composites // Ceramics International. - 2012. - Vol. 38. - P. 591 - 594. 
4. Khalil, I., Rahmati, Sh., Muhd, N., Wageeh, J. Graphene metal nanocomposites / Recent progress in electrochemical biosensing applications // Journal of Industrial and Engineering Chemistry. - 2018. - Vol. 59. - P. 425 - 439.

5. Waszkielis, K.M., Białobrzewski, I., Nowak, K.W., Dzadz, L., Dach, J. Determination of the thermal conductivity of composed material // Measurement. - 2014. - Vol.58. - P. 441 - 447.

6. Xu, H., Wu, X., Li, X. et. al. Properties of graphene-metal contacts probed by Raman spectroscopy // Carbon. - 2018. - Vol. 127. - P. 491 - 497.

7. Zhou, L., Wang, H., Zhang, J. Study on the synthesis and surface enhanced Raman spectroscopy of graphene-based nanocomposites decorated with noble metal nanoparticles // Colloids and Surfaces A: Physicochemical and Engineering Aspects. - 2013. - Vol. 430. - P. 103 - 109.

8. Korskanov, V.V., Karpova, I.L., Ruhaylo, M.V. et. al. Calorimetric module for studying the thermophysical properties of composite materials // Ceramics: science and life. - 2016. - №3(32). - P. 5 - 15.

9. Wunderlich, B. Thermal Analysis of Materials // Springer. - 2005. - 907 p.

10. Kaye, G.W., Laby, T.H. Tables of Physical and Chemical Constants // LONGMANS GREEN \& Co, London, New York, Toronto. - 1962. - 248 p.

11. Chu, K., Wang, X., Li, Y. et. al. Thermal properties of graphene/metal composites with aligned graphene // Materials and Design. - 2018. - Vol. 140. - P. 85 - 94. 